\title{
PERFORMANCE EVALUATION OF AN INCORPORATION OF A COMPACT LIQUID DESICCANT SYSTEM INTO AN EVAPORATIVE COOLING-ASSISTED 100\% OUTDOOR AIR SYSTEM
}

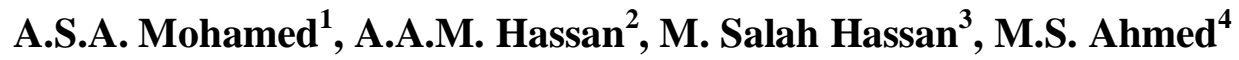 \\ ${ }^{I}$ Department of Mechanical Engineering, Faculty of Industrial Education, Sohag University, Egypt \\ ${ }^{2}$ Department of Mechanical Power Engineering and Energy, Faculty of Engineering, Minia University, Egypt \\ ${ }^{3}$ Department of Mechanical Power Engineering and Energy, Faculty of Engineering, Minia University, Egypt \\ ${ }^{4}$ Department of Mechanical Engineering, Faculty of Industrial Education, Sohag University, Egypt
}

\begin{abstract}
The primary goal of this paper is to suggest incorporation of a compact liquid desiccant system into an evaporative coolingassisted 100\% outdoor air system as an alternative proposal to the traditional vapor compression refrigeration system, especially with small loads, as well as to counteract the variation of climates. Current study presents an experimental analysis for building air conditioning system with using a LiCl aqueous solution as a liquid desiccant. Four air flow rate values are used for obtaining variable values of cooling capacity. Thermal and electrical COP is adopted to evaluate the system performance. The proposed system has the ability to improve indoor air quality, energy saving and environmental protection.
\end{abstract}

Keywords: Air conditioning; Liquid desiccant; Evaporative cooling; 100\% Outdoor air; Energy saving

\section{NOMENCLATURE}

$\mathrm{C}_{\mathrm{p}, \mathrm{w}} \quad$ specific heat of water $\left(\mathrm{kJ} / \mathrm{kg}{ }^{\circ} \mathrm{C}\right)$

ha enthalpy of air $(\mathrm{kJ} / \mathrm{kg})$

$\mathrm{m}^{\cdot} \quad$ mass flow rate $(\mathrm{kg} / \mathrm{s})$

$\mathrm{Q}_{\mathrm{c}} \quad$ cooling capacity $(\mathrm{kW})$

$\mathrm{Q}_{\mathrm{r}} \quad$ regeneration heat rate $(\mathrm{kW})$

$\mathrm{T}$ temperature $\left({ }^{\circ} \mathrm{C}\right)$

\section{Greek Symbols}

$\varepsilon_{\text {eva }} \quad$ moisture effectiveness $(\%)$

$\omega_{\mathrm{a}}$ humidity ratio of humid air $(\mathrm{kg} / \mathrm{kg})$

\section{Subscripts}

a air

$\mathrm{db} \quad$ dry bulb

i inlet

o outlet

w water

wb wet bulb

\section{INTRODUCTION}

The building sector is responsible for around 30-40\% of world total energy consumption and similar proportion of global carbon emission [1]. Heating, Ventilation and Air Conditioning (HVAC) is the major energy user in a building and consumes around $50 \%$ of the total supplied energy [1]. Air-conditioning represents an important function of the HVAC system. The need and use of air-conditioning are rapidly increasing over worldwide and normally vapor compression systems are being used for this purpose. As a consequence, the electrical consumption for air-conditioning is also increasing at a rapid rate.

Air conditioning market is currently dominated by the mechanical vapor compression refrigeration system which formed as a loop, Fig. 1 comprising an evaporator, a condenser, a compressor and an expansion valve, allows a refrigerant (e.g., R-22, R-134a, R410A) to circulate around. This kind of cycle was fully established and has been in practical use for over 100 years. Owing to its relatively long history and massive scale production, the technology presents many advantages e.g., good stability in performance, low cost and long life cycle time. However, this type of system has a major disadvantage that lies in high demand to electricity for operation of the compressor. Owing to the high dependency of fossil fuel burning in current electrical industry, this technology is regarded as neither sustainable nor environmentally friendly [2]. A promising alternative for replacing vapor compression machines, in thermal comfort applications, is evaporative cooling (EC).

Under climate conditions where the temperature is high and the humidity is low, air conditioning can be achieved by EC $[3,4]$. The EC systems alone cannot provide optimal comfort for all climates, especially high humidity ones. The applications of EC may be extended to humid climates by introducing an air drier to remove most of the water vapor from the air. The EC combined with desiccant dehumidification shows considerable promise for residential and industrial air conditioning applications. Desiccantaugmented evaporative cooling systems have gained attracted worldwide attention as an environmentally friendly 
technology for comfort air conditioning with the added advantages of simple design, robustness and low electric power consumption [5]. Both solid and liquid desiccants have been proposed, the mainly advantage of the former is its compact design. Many solid desiccant-augmented evaporative cooling cycles have been reported in the literature [6-16]. While few studies discussed the liquid desiccant based-evaporative cooling system $[17,18]$.

A liquid desiccant system is preferable because of its operational flexibility, ability to absorb inorganic and organic contaminants from air [4] and its ability also to operate under a relatively low regeneration temperature. Besides, using of brine as absorbents is frequently environmentally friend as it doesn't cause ozone depletion [5]. In spite of all of these advantages, the large size of the liquid desiccant system makes it hard to be used in the small conditioning-demanded areas. The present study adopts a new compact construction of liquid desiccant basedevaporative cooling-assisted $100 \%$ outdoor air system. The same component is used as a dehumidifier and a regenerator, so there is a time delay between their operating processes. Current study presents an experimental analysis for building air conditioning system.

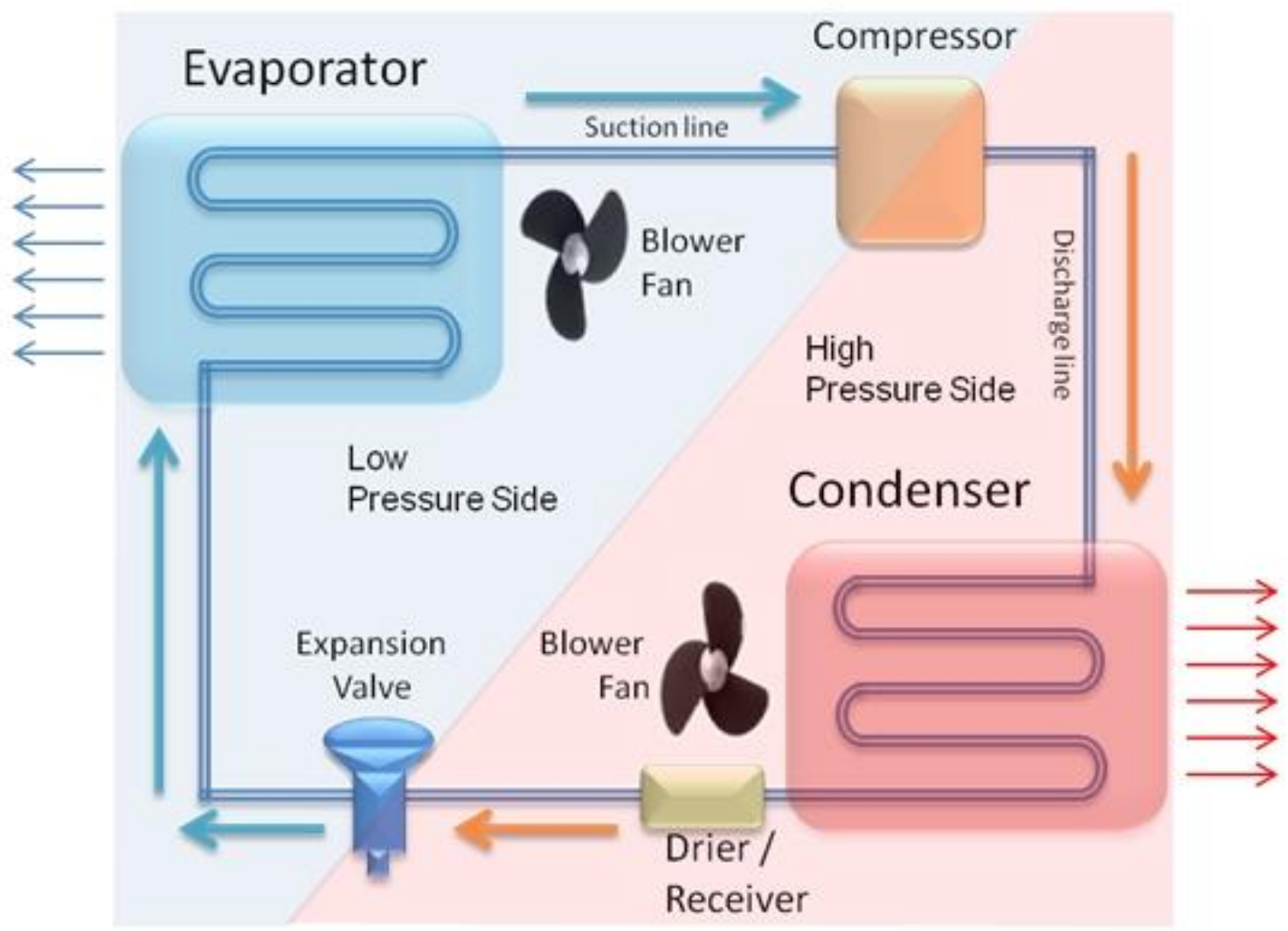

Fig 1: Conventional Vapor compression cycle

\section{EVAPORATIVE COOLER}

Evaporative cooler is considered as a simple and economic means for air conditioning. The evaporative cooler works on the principle that when dry air passes over water, some of the water will be evaporated by the air causing loss of air energy and hence the air temperature is lowered. Transfer of water continues as a result of the difference between their respective temperatures and vapor pressures. Evaporation requires heat absorption. Latent heat is absorbed by the water and is given up by the air. The air provides this energy in the form of a loss of sensible heat and hence its temperature is lowered. The net result is that the air has a lower temperature, more humidity and almost has no net change of energy.
The maximum possible dry bulb temperature reduction for air is the difference between the entering air dry bulb and wet bulb temperature. This is usually referred to as the wet bulb depression. The effectiveness of the cooler is defined as the ratio of actual reduction in dry bulb temperature to the maximum possible reduction in temperature. It can be written as:

$$
\varepsilon_{\text {ย่a }}=\frac{T_{a b, i}-T_{d b, 0}}{T_{a b, i}-T_{w b, i}}
$$

Where, $T_{d b, i}$ is the inlet air dry bulb temperature, $T_{d b, o}$ is the outlet air dry bulb temperature and $\mathrm{T}_{\mathrm{wb}, \mathrm{i}}$ is the inlet air wet bulb temperature. 
The rate of water evaporated in the cooler is the product of the flow rate of air and the difference in the inlet and outlet humidity ratio of air given by:

$$
m_{w}^{\bullet}=m_{a}^{\bullet}\left(\omega_{a, o}-\omega_{a, i}\right)
$$

It may be noted that adding water vapor is dependent on the initial humidity of air. This option is added for flexibility purpose. If air is humid, there is no need to add moisture and the air can be sent directly to the dehumidifier.

\section{PROPOSED LIQUID DESICCANT AIR CONDITIONING SYSTEM, LDACS}

\subsection{LDACS Configuration}

Figure 2 shows a schematic diagram for the proposed LDACS. The system consists of a dehumidifier/regenerator, an evaporative cooler and air fan on the process air side. It also comprises a flat plate collector, a hot water storage tank, a hot water circulation pump and a heat exchanger located in the solution tank for the purpose of heating the dilute solution before the regeneration process. Vapor compression cycle consists of a compressor, a condenser, a capillary tube and a heat exchanger (evaporator) located in the solution tank for cooling the strong solution before the dehumidification process.

\subsection{Test Chamber}

As can be seen in Fig. 3.3, a compact liquid desiccant dehumidification based-evaporative cooling system is employed to cool and dehumidify the process air (1-2-3-4$5)$. The hot and dry air (100\% outdoor) at point 1 enters the evaporative cooler and exits cooled and humidified at point 2. The humidified air at state (3) passes through the packed bed dehumidifier where the moisture absorbed by strong lithium chloride. The cool and dry air exiting from the dehumidifier at point 4 is able to satisfy the human comfort. The air is then delivered by fan (e) to the conditioned space (5). During the dehumidification process the strong lithium chloride solution of $40 \%$ concentration at $22{ }^{\circ} \mathrm{C}$ is withdrawn from the bottom of the solution tank (a) and sprayed at the top by the liquid pump (d). The solution temperature $22{ }^{\circ} \mathrm{C}$ is obtained by vapor compression cycle $(150 \mathrm{~W})$. Note that, the liquid desiccant sprayed temperature is lower than the temperature of the air inlet dehumidifier at state 3, so it is expected that the air outlet temperature (4) is lower than that of the inlet (3). Furthermore, low desiccant temperature results in decreasing its vapor pressure and that, in turn, increases the driving force between the air and the desiccant. After a certain time the liquid desiccant becomes dilute and the regeneration process should be carried out.

The regeneration process (6-3-4-7) operates according to the following steps. At the beginning, the evaporative cooling has to be closed. The water is heated by a flat plate solar collector $\left(1.5 \mathrm{~m}^{2}\right)$, and stored in a tank. The liquid desiccant is heated by hot water $\left(74{ }^{\circ} \mathrm{C}\right)$ that is withdrawn from the water storage tank and passed through a water heat exchanger (b) submerged in the solution tank (a). The heating exchange between the water and the desiccant continues until the temperature of liquid desiccant reaches $68{ }^{\circ} \mathrm{C}$. And then the liquid pump (d) withdraws the hot and dilute solution from the tank (a) and sprays it at the top. Hot and dry outside air is withdrawn from point 6 to point 4 by fan (e) to regenerate the dilute solution where the absorbent moisture is released from weak desiccant to air. The air exiting from the regeneration process is exhausted at point 7 to atmosphere by fan (e). Then the regenerated solution accumulates in the bottom tank (a) and has to be cooled, preferably using small vapor compression cycle, to its initial condition for the dehumidification process. Observe that the liquid to air flow rate ratios of 2, 4 are constant during the dehumidification and the regeneration processes respectively.

\section{COST REDUCTION}

Liquid desiccant cooling technologies generally incur higher initial cost than the equivalent conventional system. Cost reduction potential can be achieved through simplified cycle selection, size reduction and increasing thermal efficiency. The latter is particularly important where capital intensive solar collectors are used to provide the required heat. Size reduction can be achieved through optimizing air-flow-rates and velocities. In the compact system proposed, the separation of operating time between the dehumidification and the regeneration processes contributes significantly in reducing size and initial cost where the same unit is used for the two processes. The Only disadvantage of this system is that it requires more amount of liquid desiccant to recover high cooling load. 


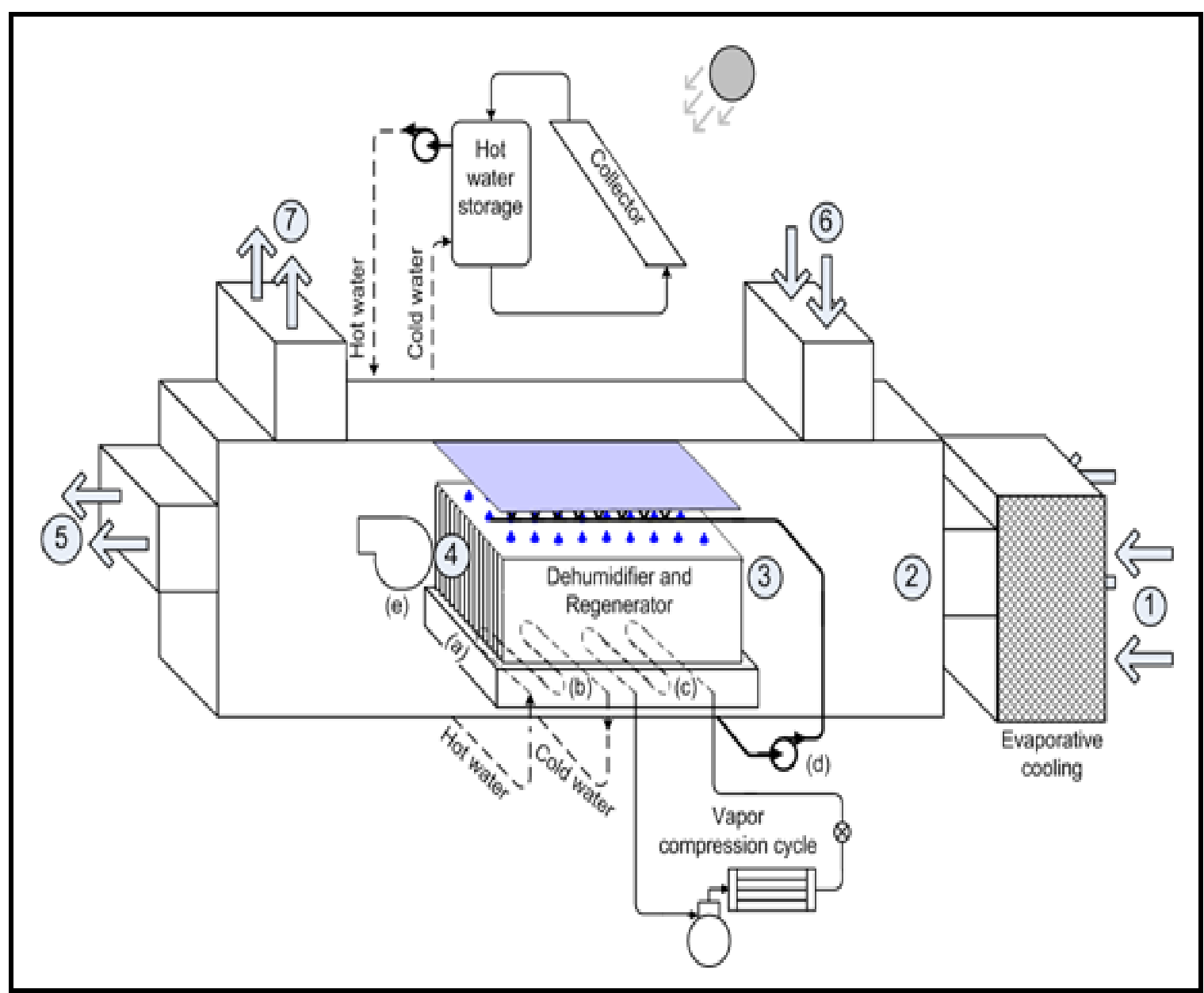

Fig 2: A schematic diagram of proposed liquid desiccant air conditioning system

\section{RESULTS AND DISCUSSION}

\subsection{Thermal Power Required for Heating \\ Regenerating Desiccant}

The heat required to increase liquid desiccant temperature from $22{ }^{\circ} \mathrm{C}$ to $68{ }^{\circ} \mathrm{C}$ to regenerate dilute solution was estimated and found from Eq. 3 where hot water is used for heating the liquid desiccant.

$Q_{r}=m_{w}^{\bullet} C_{p, w}\left(T_{w, i}-T_{w, o}\right)$

\subsection{Psychrometric Analysis of the LDACS}

The LDACS cycle comprises two main alternating processes. The first process involves the air dehumidification cycle where the moist air is dried by the liquid desiccant to a comfortable condition. The second one is the regeneration process of the dilute solution by heating it and the outside air passes, thus, the solution is reconcentrated to the original condition. Figure 3 shows the dehumidification process of an air conditioning cycle of the proposed LDACS plotted on the psychrometric chart. Table 1 shows the state points for the LDACS at different values of the air flow rate.
The air conditioning cycle is represented by (1-2-3-4-5) with 1-2 is the process in the evaporative cooler and 3-4 is the process in the dehumidifier. To obtain the maximum cooling capacity from the LDACS, during the dehumidification process, the liquid desiccant temperature must be lower than the air temperature outlet from the evaporative cooler. It is found that the small vapor compression cycle is the most suitable way for cooling the liquid. 


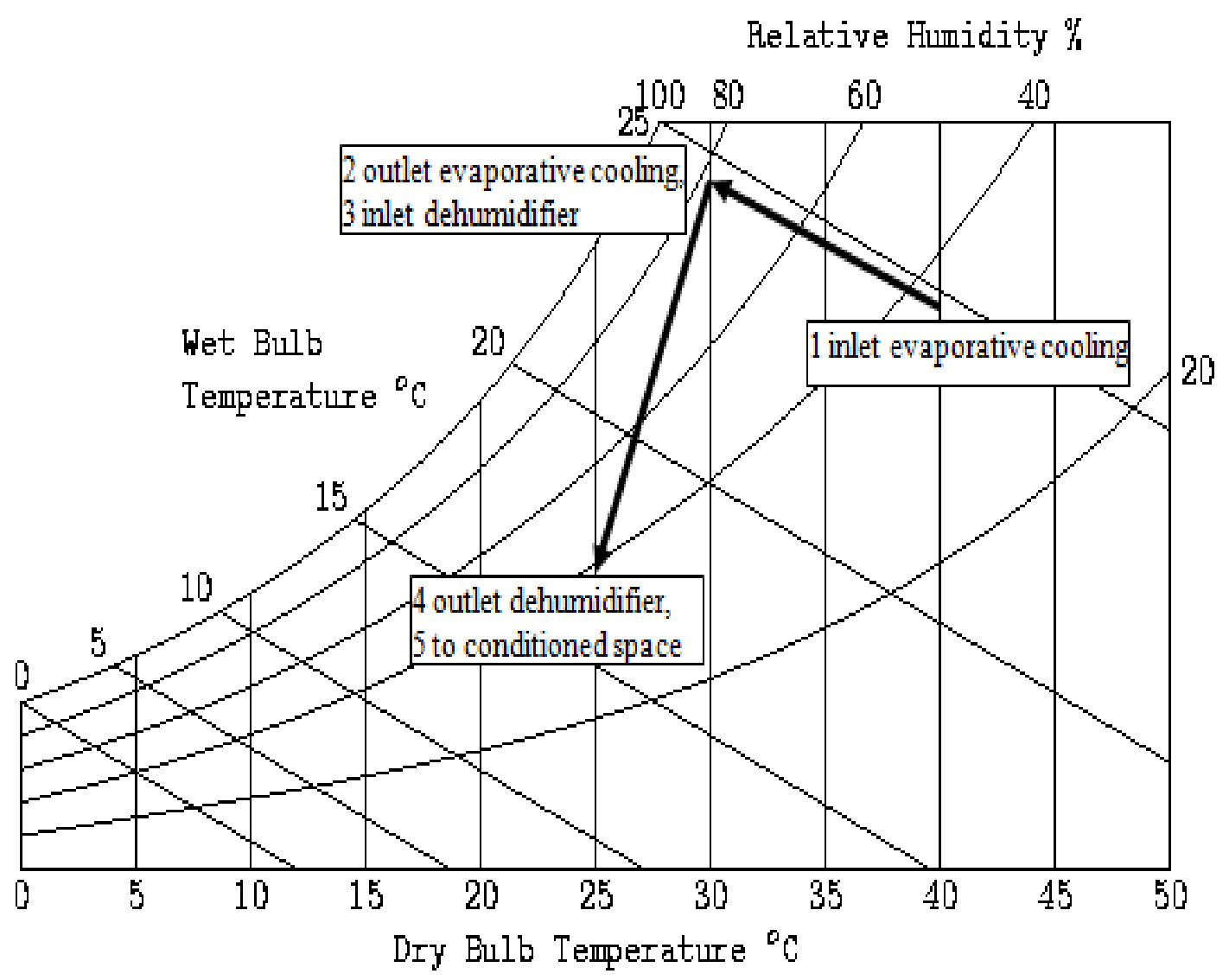

Fig 3: Air processes on the psychrometric chart

Table-1: State points of inlet and outlet processes for the LDACS

\begin{tabular}{|c|c|c|c|c|c|c|c|}
\hline $\begin{array}{l}\text { State } \\
\text { point }\end{array}$ & $\begin{array}{l}\text { Dry bulb, } \\
{ }^{\circ} \mathrm{C}\end{array}$ & $\begin{array}{l}\text { Wet bulb, } \\
{ }^{\circ} \mathrm{C}\end{array}$ & $\begin{array}{l}\text { Dew } \\
\text { bulb, } \\
{ }^{\circ} \mathrm{C}\end{array}$ & $\begin{array}{l}\text { Relative } \\
\text { humidity, \% }\end{array}$ & $\begin{array}{l}\text { Humidity ratio, } \\
\mathrm{g}_{\mathrm{w}} / \mathrm{kg}_{\mathrm{da}}\end{array}$ & Enthalpy, kJ/kg & $\begin{array}{l}\text { Specific } \\
\text { volume, } \\
\mathrm{m}^{3} / \mathrm{kg}_{\mathrm{da}}\end{array}$ \\
\hline \multicolumn{8}{|c|}{$\mathrm{m}_{\mathrm{a}}=0.109 \mathrm{~kg} / \mathrm{s}$} \\
\hline 1 & 39.5 & 24.5 & 18.34 & 29.61 & 13.3 & 74.073 & 0.905 \\
\hline 2,3 & 26.4 & 23.9 & 22.57 & 77.78 & 17.4 & 71.441 & 0.874 \\
\hline 4,5 & 23.5 & 15.3 & 9.42 & 41.14 & 7.4 & 42.466 & 0.850 \\
\hline \multicolumn{8}{|c|}{$\mathrm{m}_{\mathrm{a}}=0.164 \mathrm{~kg} / \mathrm{s}$} \\
\hline 1 & 40.1 & 24.5 & 18.04 & 28.15 & 13.1 & 74.040 & 0.906 \\
\hline 2,3 & 27.3 & 24.0 & 22.58 & 75.99 & 17.4 & 71.862 & 0.875 \\
\hline 4,5 & 24.5 & 16.0 & 10.26 & 41.01 & 7.8 & 44.604 & 0.854 \\
\hline \multicolumn{8}{|c|}{$\mathrm{m}_{\mathrm{a}}=0.218 \mathrm{~kg} / \mathrm{s}$} \\
\hline 1 & 39.4 & 24.3 & 18.01 & 29.16 & 13.1 & 73.250 & 0.904 \\
\hline 2,3 & 27.0 & 23.6 & 22.1 & 75.14 & 16.9 & 70.256 & 0.873 \\
\hline 4,5 & 25.2 & 16.6 & 10.94 & 41.17 & 8.2 & 46.263 & 0.856 \\
\hline \multicolumn{8}{|c|}{$\mathrm{m}_{\mathrm{a}}^{\circ}=0.273 \mathrm{~kg} / \mathrm{s}$} \\
\hline 1 & 38.9 & 24.3 & 18.26 & 30.42 & 13.3 & 73.274 & 0.903 \\
\hline 2,3 & 26.9 & 23.1 & 21.39 & 72.42 & 16.2 & 68.302 & 0.872 \\
\hline 4,5 & 25.6 & 17.0 & 11.49 & 41.71 & 8.5 & 47.468 & 0.858 \\
\hline
\end{tabular}




\subsection{Performance of the LDACS}

The following describes the performance of the proposed LDACS.

\subsubsection{Cooling Capacity}

The cooling capacity is the energy rate gained by the air stream from point 1 to point 5, as shown in Fig. 3 The cooling capacity was estimated and found from Eq. 4. Table 2 indicates the cooling capacity for each air flow rate value. The change of cooling capacity $\mathrm{Q}_{c}$ with air flow rate is shown in Fig. 4 As indicated by the figure, air flow rate $m_{a}^{\cdot}$ has strong effect on $\mathrm{Q}_{\mathrm{c}}$. The curve seems approximately linier because the liquid to air flow rate ratio $\left(\mathrm{m}_{\mathrm{s}}^{*} / \mathrm{m}_{\mathrm{a}}^{\cdot}=2\right)$ is constant during the dehumidification process at the four air flow rates. In simplification, $\mathrm{Q}_{\mathrm{c}}$ is expressed by Eq. 5 .

$$
\begin{aligned}
& Q_{c}=m_{a}^{\bullet}\left(h_{a, 1}-h_{a, 5}\right) \\
& C_{\varepsilon}=7.045-21.95\left(0.273-m_{a}^{\bullet}\right)
\end{aligned}
$$

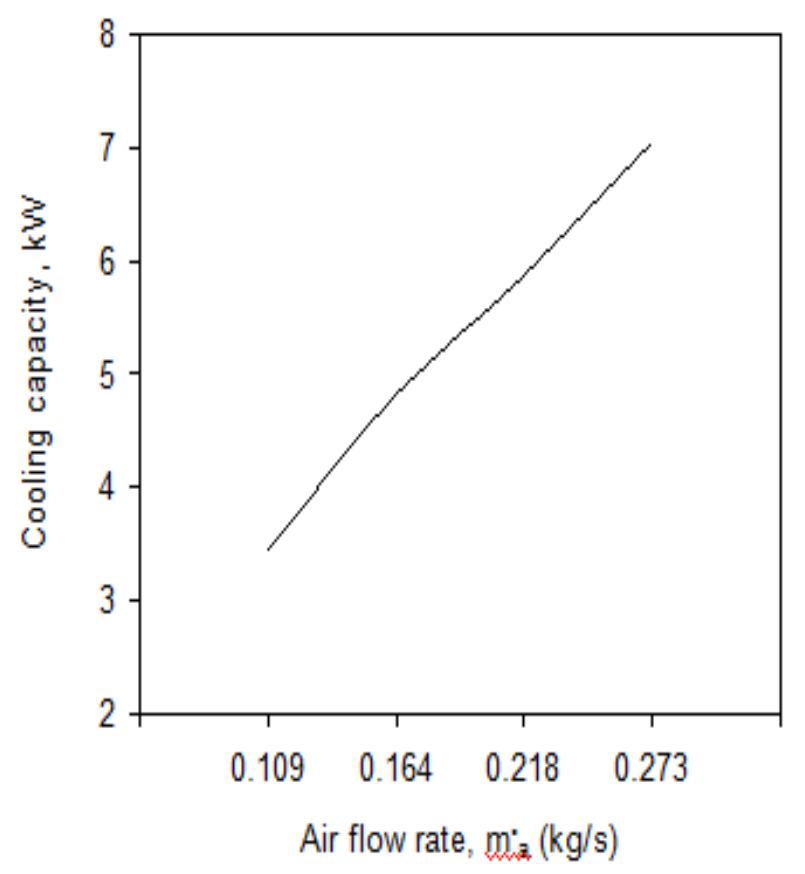

Fig 4: Influence of air flow rate on cooling capacity

\subsubsection{Coefficient of Performance, COP}

In the present study, two definitions of the COP were adopted. One thermal COP is defined as the ratio of cooling capacity to the energy input to the system. Energy input includes electrical energy used to circulate air, water and desiccant, and the energy used for regeneration Eq. 6. The other electrical COP is defined as the ratio of useful cooling to electrical energy consumption of the system Eq. 7. The values of the thermal and electrical COP are summarized in table 2 .

$$
\begin{aligned}
C O P_{t h} & =\frac{\text { cooling capacity }}{\text { power consumption }+ \text { heat input }} \\
C O P_{e l} & =\frac{\text { cooling capacity }}{\text { power consumption }}
\end{aligned}
$$

The electrical COP of the compact system was significantly improved in comparison to the previous configurations, reaching 4.4 as a mean value at the air flow rate $0.273 \mathrm{~kg} / \mathrm{s}$. Typical mean values of the previous configurations ranged from 2 to 2.9 [19]. Due to the increased cooling performances, the electrical COP of the system, built by Finocchiaro [9], was clearly improved reaching 4.6. The mean value of the current thermal COP ranges from 1.3 to 1.6, while in a previous study [7], the value recorded 0.75 , and in another one, the value reached 1.8 [9].

Table-2: Values of Cooling capacity and COP obtained from the practical experiments

\begin{tabular}{|l|l|l|l|l|}
\hline Item & $\begin{array}{l}\mathrm{m}_{\mathrm{a}}= \\
0.109 \\
\mathrm{~kg} / \mathrm{s}\end{array}$ & $\begin{array}{l}\mathrm{m}_{\mathrm{a}}=.164 \\
\mathrm{~kg} / \mathrm{s}\end{array}$ & $\begin{array}{l}\mathrm{m}_{\mathrm{a}}= \\
0.218 \\
\mathrm{~kg} / \mathrm{s}\end{array}$ & $\begin{array}{l}\mathrm{m}_{\mathrm{a}} \\
0.273 \\
\mathrm{~kg} / \mathrm{s}\end{array}$ \\
\hline $\begin{array}{l}\text { Cooling } \\
\text { capacity, } \mathrm{kW}\end{array}$ & 3.445 & 4.828 & 5.883 & 7.045 \\
\hline Electrical COP & 3.2 & 3.7 & 4 & 4.4 \\
\hline Thermal COP & 1.3 & 1.4 & 1.4 & 1.6 \\
\hline
\end{tabular}

\subsubsection{Energy Saving}

Figure 5 shows a comparison of the system energy consumptions of the LDACS and the package conventional system under the condition of operating the system for 8 hours. Because the LDACS does not require a compressor, the energy consumption occurs only in the fans, pumps, and auxiliary heater operation, while the compressor is an essential component for the conventional system. Consequently, the proposed system consumes $21 \%, 32 \%$, $44 \%$ less operating energy than the conventional system at cooling capacity $27.6,38.6$ and $47.1 \mathrm{~kW} . \mathrm{h}$ respectively, while at cooling capacity $56.4 \mathrm{~kW}$.h the energy consumed is nearly half of the operating energy with respect to the conventional system, saving approximately $44 \%$ of the system operating energy. For knowledge, Kim [17] achieved less than half of the operating energy compared with the conventional system recording $51 \%$ energy saving.

\section{CONCLUSION}

In this paper, performance evaluation of an incorporation of a compact liquid desiccant system into an evaporative cooling-assisted $100 \%$ outdoor air system has been predicted. The following main conclusions emerged from this study.

- In the compact system proposed, the separation of operating time between the dehumidification and the regeneration processes contributes significantly in reducing size and initial cost where the same unit is used for the two processes. 
- The electrical COP of the compact system was improved significantly reaching 4.4 as a mean value at the air flow rate $0.273 \mathrm{~kg} / \mathrm{s}$. The mean value of the thermal COP ranges from 1.3 to 1.6.

- The LDACS showed $44 \%$ less operating energy than the conventional system.

The results obtained herein are useful for the design and development of compact liquid desiccant cooling systems which require much less electric power consumption. Further work in this direction is in progress.

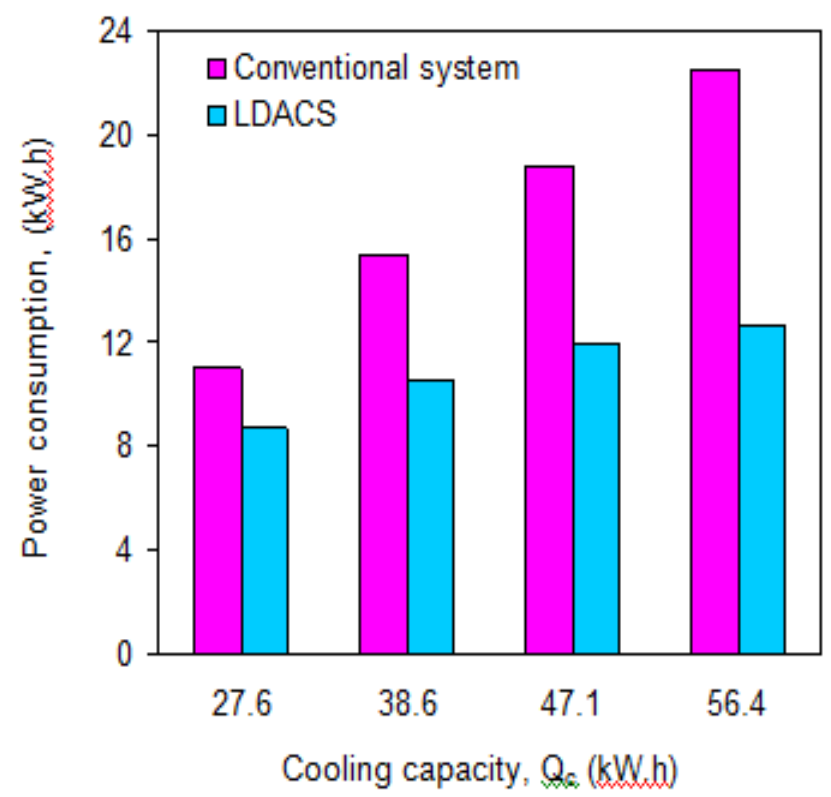

Fig 5: Comparison of power consumption between LDACS and conventional system

\section{REFERENCES}

[1]. Luis P.L., Jose O. and Christine P., A review on buildings energy consumption information, Energy and Buildings 40 (3) (2008) 394-8.

[2]. Zhiyin D., Changhong Z., Xingxing Z., Mahmud M. and Xudong Z., Indirect evaporative cooling: Past, present and future potentials, Renewable and Sustainable Energy Reviews, 16 (2012) 6823-6850.

[3]. Epstien M., Grolmes M., Davidson K. and Kosar D., Desiccant cooling system performance: A simple approach, Journal of Solar Energy Engineering 107 (1) (1985) 21-28.

[4]. Biswas P., Kim S. and Mills A.F., A compact low pressure drop desiccant bed for solar air conditioning applications: analysis and design, Journal of Solar Energy Engineering 106 (2) (1984) 153-158.

[5]. Dhar P.L., Kaushik S.C. and Jain S., Thermodynamic analysis of desiccant-augmented evaporative cooling cycles for Indian conditions, ASHRAE Transactions 101 (1) (1995) 735-749.

[6]. Jain S., Dhar P.L. and Kaushik S. C., Evaluation of solid-desiccant-based evaporative cooling cycles for typical hot and humid climates, International Journal of Refrigeration 18 (5) (1995) 287-296.
[7]. Mahmoud S.A., Air conditioning of industrial space using activated alumina extracted from aluminium dross tailings as a desiccant, Ph.D. Dissertation, Department of Mechanical Engineering, Assiut University, Egypt.

[8]. Bongs C., Morgenstern A. and Henning H., Advanced performance of an open desiccant cycle with internal evaporative cooling, Energy Procedia 30 ( 2012 ) 524 - 533. [9]. Finocchiaro P., Beccali M. and Nocke B., Advanced solar assisted desiccant and evaporative cooling system equipped with wet heat exchangers, Solar Energy 86 (2012) 608-618.

[10]. La D., Li Y., Dai Y.J., Ge T.S. and Wang R.Z., Development of a novel rotary desiccant cooling cycle with isothermal dehumidification and regenerative evaporative cooling using thermodynamic analysis method, Energy 44 (2012) 778-791.

[11]. Preisler A. and Brychta M., High potential of full year operation with solar driven desiccant evaporative cooling systems, Energy Procedia 30 ( 2012 ) 668 - 675.

[12]. Aprile M., Scoccia R. and Motta M., Modelling and control optimization of a solar desiccant and evaporative cooling system using an electrical heat pump, Energy Procedia 30 ( 2012 ) 478-489.

[13]. Oldsworthy M. and White S., Optimisation of a desiccant cooling system design with indirect evaporative cooler, International Journal of Refrigeration 34 (2011) 148158.

[14]. Heidarinejad G. and Pasdarshahri H., Potential of a desiccant-evaporative cooling system performance in a multi-climate country, International Journal of Refrigeration 34 (2011) 1251-1261.

[15]. Vitte T., Brau J., Chatagnon N. and Woloszyn M., Proposal for a new hybrid control strategy of a solar desiccant evaporative cooling air handling unit, Energy and Buildings 40 (2008) 896-905.

[16]. La D., Dai Y., Li Y., Ge T. and Wang R., Study on a novel thermally driven air conditioning system with desiccant dehumidification and regenerative evaporative cooling, Building and Environment 45 (2010) 2473-2484.

[17]. Kim M., Park J. and Jeong J., Energy saving potential of liquid desiccant in evaporative cooling- assisted 100\% outdoor air system, Energy 59 (2013) 726-736.

[18]. Al-Sulaiman F.A., Gandhidasan P. and Zubair S.M., Liquid desiccant based two-stage evaporative cooling system using reverse osmosis ( $\mathrm{RO})$ process for regeneration, Applied Thermal Engineering 27 (2007) 2449-2454.

[19]. Beccali M., Finocchiaro P., Luna M. and Nocke B., Monitoring of a solar desiccant cooling system in Palermo (Italy), First results and test planning. In: Intern. Conference EUROSUN, Lisbona, 7-10 October 2008, pp. 316-317, ISBN 978-972-95854-7-0 (Abstract). 